\title{
Explaining the Gender Gap in Waiting Times for Scheduled Surgery in the Portuguese National Health Service
}

\author{
Joana Cima ${ }^{a}$ Paulo Guimarães ${ }^{a, b}$ Álvaro Almeida ${ }^{a, b}$ \\ a Universidade do Porto, Faculdade de Economia, Porto, Portugal; ${ }^{b}$ cef.up, Center for Economics and Finance at the \\ University of Porto, Porto, Portugal
}

\section{Keywords}

Waiting times · Scheduled surgery - Gender gap · Gelbach's decomposition · Portugal

\begin{abstract}
Objective: This paper evaluates the gender gap in waiting times for scheduled surgery, using information on 2.6 million surgical episodes in Portuguese National Health Service hospitals covering the period from 2011 to 2015. Methodology: We estimated the gross gender gap, i.e., the differential between the waiting times of men and women, and then add several explanatory variables that can account for this difference to estimate an adjusted gender gap. The variables are added in a way that permits the most flexible parametric specification. Next, we used Gelbach's decomposition to understand the contribution of each variable to the difference between the gross and the adjusted gender gaps. Results: The gross gender gap of $10 \%$ is reduced to a $3 \%$ adjusted gender gap after accounting for observable explanatory factors. Gelbach's decomposition shows that patient priority and hospital-fixed effects are the variables that contribute the most to the explained component of the gap. The analysis suggests that men tend to be ranked with more severe
\end{abstract}

priorities, and that there are hospital specificities that cause men to have shorter waiting times. Conclusions: Overall, we identified a gender bias against women in surgery waiting times, but the size of the bias is smaller than was previously suggested in the literature.

(c) 2021 The Author(s). Published by S. Karger AG, Basel on behalf of NOVA National School of Public Health

Explicar a diferença de género nos tempos de espera para cirurgia programada no Serviço Nacional de Saúde Português

\section{Palavras Chave}

Tempos de espera . Cirurgia programada . Diferença de género · Decomposição de Gelbach · Portugal

\section{Resumo}

Objetivo: Este trabalho avalia a diferença de género nos tempos de espera para cirurgias programadas, usando cerca de 2.6 milhões de observações sobre os episódios cirúrgicos que ocorreram nos hospitais do Serviço Nacional de Saúde Português entre 2011 e 2015. Metodologia: karger@karger.com www.karger.com/pjp

Karger

BOPEN ACCESS (c) 2021 The Author(s). Published by S. Karger AG, Basel on behalf of NOVA National School of Public Health

This article is licensed under the Creative Commons AttributionNonCommercial-NoDerivatives 4.0 International License (CC BYNC-ND) (http://www.karger.com/Services/OpenAccessLicense). Usage and distribution for commercial purposes as well as any distribution of modified material requires written permission.
Joana Cima

Faculdade de Economia, Universidade do Porto

Rua Dr. Roberto Frias

PT-4200-464 Porto (Portugal)

joanacima.phd@fep.up.pt 
Estimamos o diferencial bruto entre géneros nos tempos de espera, e depois adicionamos variáveis de controlo que expliquem a diferença para estimar um diferencial ajustado. As variáveis são adicionadas de maneira a permitir uma especificação paramétrica mais flexível. Em seguida, usamos a decomposição de Gelbach para entender a contribuição de cada variável para a divergência entre os diferenciais de género bruto e ajustado. Resultados: 0 diferencial bruto de $10 \%$ entre géneros é reduzido para um diferencial ajustado de $3 \%$ depois de considerado o efeito das variáveis explicativas observadas. A decomposição de Gelbach mostra que a prioridade do paciente e os efeitos fixos hospitalares são as variáveis que mais contribuem para a componente explicada da diferença. A análise sugere que os homens tendem a ser classificados com prioridades mais severas e que existem especificidades hospitalares que fazem com que os homens tenham tempos de espera mais curtos. Conclusões: No geral, os nossos resultados identificam um viés de género contra as mulheres, mas a dimensão do viés é menor do que sugerido pela literatura anterior.

(c) 2021 The Author(s) Published by S. Karger AG, Basel on behalf of NOVA National School of Public Health

\section{Introduction}

Equity in access is a central theme in universal health care systems [1], where the severity of a patient's clinical condition is supposed to be the most relevant factor in explaining waiting times. However, there is evidence that a set of variables besides severity (e.g., gender, age, and income) have a significant impact on access [2-4].

In recent decades, the issue of gender gap or gender bias has gained relevance in health research [5] and has been widely discussed in the literature relating to diverse topics such as mortality, morbidity, or health care utilisation [6-10].

Although gender bias corresponds to an unequal treatment of individuals based on their gender, Alspach [9] noticed that the gender bias in the health care literature predominantly refers to when "female patients are assessed, diagnosed, referred, and treated not only differently but at a lower level of quality" which may cause worsening of women's health status. Underestimating or misunderstanding women's health conditions, differences in the way men and women perceive and experience their illness, unconscious prejudice, or explicit discrimination are some of the reasons for the gender bias $[5,9]$. This bias reveals gender discrimination when the gap in health and health care provided to men and women is not explained by legitimate differences that result from biological differences, anatomy, or risk behaviour $[9,11]$.

Understanding the factors that condition access to health care by gender is an important issue in health policy [12] since it is essential to develop policies that improve the health care provided to men and women as well as the health outcomes, and increase efficiency by optimizing hospital resources [13].

However, the gender bias still receives little attention from the decision-makers and researchers [14]. The literature on inequality regarding waiting times has been more focused on socioeconomic status [1, 3, 4, 15-18] rather than on how gender issues, such as the distinct patterns in access to health and health care utilisation, disease and disease severity, the type and quality of treatments delivered, and gender pay gaps [12,19-23] explain the different waiting times of men and women.

Data on waiting times in the literature also tends to ignore the distinction between "gender differences" and "gender bias." The difference between the average waiting times for men and women, the "unadjusted gender gap," can be explained by control variables that reflect legitimate differences between genders. The "unexplained" or "adjusted" gender gap, consisting of the part of the gap that is not explained by such control variables, may indicate a gender bias that amounts to discrimination.

Our study contributes to the gender bias in the health care literature by analysing the different waiting times for scheduled surgery between men and women as well as the sources and nature of the observed gender gap.

Significant waiting times for scheduled procedures is a feature usually found in health systems of the National Health Service (NHS) type, i.e., those mainly financed by taxes and with reduced user charges $[15,24]$. Since all individuals have the right to access and to be treated by the NHS, it is common that demand consistently exceeds supply and this can translate into long waiting times and waiting lists. In Portugal, over the years, waiting lists and waiting times have been an important health policy topic [25] which led to the creation of SIGIC (the Portuguese acronym for "Integrated Management System for the Surgery Waiting List") in 2004.

The main goals of SIGIC were to: (1) reduce waiting times, (2) ensure equity of access, (3) promote overall efficiency of the system, and (4) provide information quality and transparency [26].

In the years after SIGIC was created, there was a decrease in waiting times [25], but in recent years have wit- 
Fig. 1. Median waiting times (days) for surgery between 2011 and 2015 .

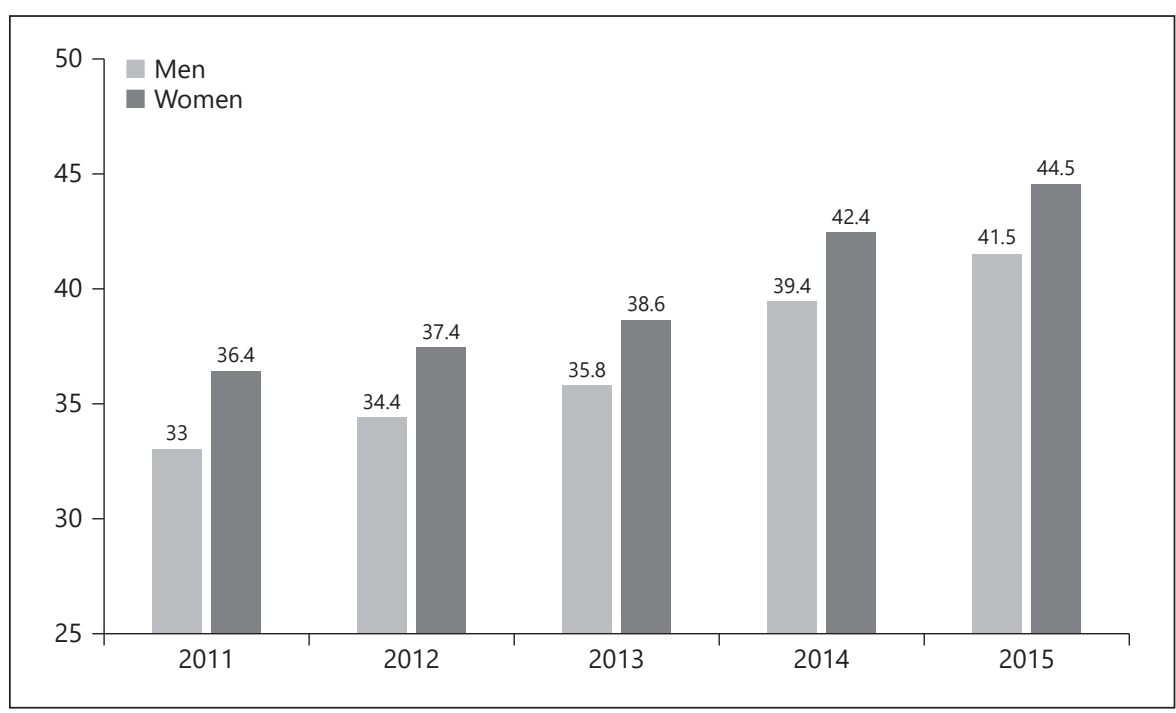

Table 1. Descriptive statistics: waiting times for surgery

\begin{tabular}{|c|c|c|c|c|c|c|}
\hline & \multirow[t]{2}{*}{$N(\%)$} & \multicolumn{5}{|c|}{ Waiting times, days } \\
\hline & & mean & median & $\mathrm{SD}$ & minimum & maximum \\
\hline Men & $1,145,341(42.57)$ & 71.36 & 36.51 & 95.92 & 0 & 3,665 \\
\hline Women & $1,545,389(57.43)$ & 75.60 & 40.00 & 102.63 & 0 & $3,707.35$ \\
\hline Total & $2,690,730(100.00)$ & 73.80 & 38.47 & 99.85 & 0 & $3,707.35$ \\
\hline
\end{tabular}

nessed a reversal of this trend, with median waiting times for surgery increasing [27] (Fig. 1).

Figure 1 also shows that women wait longer than men for scheduled surgery. However, one must control for a set of confounding variables to understand the source of this observed differential before one may conclude whether or not SIGIC guarantees gender "equity of access."

\section{Data and Methods}

\section{Data}

This study examined waiting times for all patients undergoing surgery in the Portuguese NHS in 2011-2015 by using the data on all patients registered in the SIGIC. SIGIC data was provided by the ACSS (the Portuguese Central Administration of the Health System). Waiting times correspond to the period elapsed from the moment of entry in the list until the patient was treated. ${ }^{1}$

The descriptive statistics of waiting times across genders presented in Table 1 show that women undergo a greater number of surgeries and have longer waiting times (both average and median values). ${ }^{2}$

Explaining the Gender Gap in Waiting Times for Surgery

\section{Methods}

To understand how gender influences waiting times, we start with a basic econometric specification which provides the "unadjusted gender gap" ( $\left.\beta^{\text {unadjusted }}\right)$ :

Equation 1: $Y=\beta^{\text {unadjusted }} G+\varepsilon$

where $Y$ corresponds to a vector of waiting times (in logs) and $G$ corresponds to a gender dummy, in which male is the reference category for gender ( $G=0$ for males). ${ }^{3}$ If $\beta^{\text {unadjusted }}=0$, this means that there is no evidence of a gender gap and waiting times are randomly distributed across genders, while $\beta^{\text {unadjusted }}>0$ indicates that, on average, waiting times are longer for women, i.e., there is a gender gap that favours men. $\beta^{\text {unadjusted }}<0$ indicates a gender gap favouring women.

Adding additional covariates to Equation 1 should not change the estimate of $\beta^{\text {unadjusted }}$ unless these covariates are unevenly dis-

1 Since the database is anonymised, we are unable to follow-up the patients to infer whether they were submitted to $>1$ surgery in the period under analysis. 2 Additional descriptive statistics will be made available upon request.

3 We employed the logarithmic transformation of waiting times to deal with skewed data and reduce the influence of outliers. Since the logarithm of zero is not defined, the waiting times equal to zero have been replaced by half of the minimum waiting times when excluding zeros. These observations represent $0.72 \%$ of the total sample. 
tributed across gender. This means that, for example, if waiting times across hospitals are similarly distributed by gender, then adding fixed effects for hospitals should not affect the estimate of $\beta^{\text {unadjusted }}$.

Thus, to understand the sources of the gender gap, we add to Equation 1 all observable sources of heterogeneity that may be unevenly distributed across gender, and estimate the following econometric model:

Equation 2: $Y=\beta^{\text {adjusted }} G+X \beta+\varepsilon$

where $\beta^{\text {adjusted }}$ corresponds to the "adjusted" or "unexplained" gender gap, and $X$ is a matrix $(N \times k)$ containing a set of covariates, all of them introduced as fixed effects. If $\beta^{\text {adjusted }}=0$ then differences across genders from Equation 1 are fully explained by the added covariates. In this case, the source of the gender gap can be traced to the considered heterogeneity sources. $\beta^{\text {adjusted }} \neq 0$ means that there are unexplained differences that remain between men and women that are not linked to the heterogeneity considered in the model.

We have accounted for all sources of heterogeneity observable in our data, and control for the severity of a patient's condition using the patient's initial priority ${ }^{4,5}$ and cancer indicator, speciality and type of surgical procedure, hospital, municipality, patient's age, and year.

Kaarboe and Carlsen [15] used gender, age, and municipality to assign patients to population cells and obtain income and educational levels, given their inability to know the socioeconomic status of each patient. In line with this, we estimate an additional model that includes an interaction of the municipality and patient's age-fixed effects to better control for the socioeconomic status.

Estimation of Equation 2 is not straightforward. ${ }^{6}$ Some of the variables referred to above, such as the surgical procedure, place of residence, or interaction between municipality and age-fixed effects, have high dimensions (i.e., comprising hundreds or even thousands of categories). The high dimensionality of these variables makes it difficult to estimate the model by ordinary least squares (OLS).

Thus, we employ the high-dimensional fixed-effects algorithm to overcome the computational restraints, as proposed by Guimarães and Portugal [28]. With this approach, we are able to obtain estimates regardless of the number of high-dimensional fixed effects that are considered. ${ }^{7}$

4 The clinical priority for surgery corresponds to the severity levels attributed to the patient, based on their clinical situation or need of treatment. Level 1: the patient can wait up to 270 days for the surgery, or 60 days in the case of an oncological disease (less severe priority level). Level 2: the surgical treatment cannot exceed 60 days, or 45 days in case of an oncological disease. Level 3: surgery has to be carried out within a maximum of 15 days. Level 4: surgery has to be performed within a maximum of 3 days (most severe priority level; https://dre.pt/application/conteudo/66807918).

5 We must note priority level is the best variable we have to measure the severity of the clinical condition, although clinical priority can also be affected by the way patients report their clinical condition.

6 We include all variables as fixed effects, i.e., a dummy variable is created for each category of each variable.

7 We perform robustness checks to ascertain the consistency of the adjusted gender gap ( in Robustness Checks in the Results section).

8 Also, $\hat{\theta}_{2}^{\text {hospital }} / \hat{\delta}^{\text {gender }} 100$ gives us the percentage contribution of hospitals to the explained gender gap.
Table 2. Estimation of the unadjusted and adjusted model

\begin{tabular}{llll}
\hline & Equation 1 & Equation 2 & $\begin{array}{l}\text { Equation 2 with } \\
\text { interaction }\end{array}$ \\
\hline$\hat{\beta}$ & $+0.1059^{* * *}$ & $+0.0313^{* * *}$ & +0.0318 \\
& $(0.0027)$ & $(0.0025)$ & $(0.0025)$ \\
\hline Observations & $2,690,730$ & $2,689,204$ & $2,687,797$ \\
Covariates & No & Yes & Yes \\
Year & & $X$ & $X$ \\
Hospital & & $X$ & $X$ \\
Municipality & & $X$ & \\
Procedure code & & $X$ & $X$ \\
Priority & $X$ & $X$ \\
Age & $X$ & $X$ \\
Specialty & $X$ & $X$ \\
Cancer & $X$ & $X$ \\
Municipality & Age & &
\end{tabular}

*** $p<0.01$. The robust standard errors are shown in parentheses.

In addition, we seek to investigate which factors explain the gender gap regarding access to surgical treatment, and to what extent. To observe the contribution of each of the covariates to the explained gender gap $\left(\hat{\delta}^{\text {gender }}=\hat{\beta}^{\text {unadjusted }}-\hat{\beta}^{\text {adjusted }}\right)$, we use the unambiguous decomposition proposed by Gelbach [29]. According to Gelbach [29] and Cardoso et al. [30], the explained gender gap, $\hat{\delta}^{\text {gender }}$, can be decomposed according to Equation 3 .

Equation 3: $\hat{\delta}^{\text {gender }}=\hat{\theta}_{1}^{\text {year }}+\hat{\theta}_{2}^{\text {hospital }}+\hat{\theta}_{3}^{\text {municipality }}+\hat{\theta}_{4}^{\text {procedure }}$ $+\hat{\theta}_{5}$ priority $+\hat{\theta}_{6}^{\text {age }}+\hat{\theta}_{7}^{\text {speciality }}+\hat{\theta}_{8}^{\text {cancer }}$

The coefficients $\hat{\theta}_{1}{ }^{\text {year }}, \hat{\theta}_{2}{ }^{\text {hospital }}, \ldots$, and $\hat{\theta}_{8}{ }^{\text {cancer }}$ are computed by OLS and correspond to the contribution of each group of covariates to the explained part of the gender gap. For example, $\hat{\theta}_{2}{ }^{\text {hospital }}$ $>0$ means that there is a higher concentration of women in hospitals with longer waiting times. This conclusion is reversed if $\hat{\theta}_{2}{ }^{\text {hospital }}<0$. Finally, $\hat{\theta}_{2}^{\text {hospital }}=0$ means that hospital does not contribute to the explained gender gap. ${ }^{8}$ The interpretation of the other coefficients is similar. For more details on the implementation of Gelbach's decomposition in a similar context, see Cardoso et al. [30].

Stata v14 software was employed for the econometric analysis, and Equation 2 was estimated using the user-written Stata command "reghdfe" that implements the algorithm of Correia [31].

\section{Results}

\section{General Results}

Table 2 shows the results of the estimation of Equations 1 and 2. The first column refers to the estimation of the unadjusted model (Equation 1), and the second column refers to the estimation of Equation 2 in which all 
Table 3. Gelbach's decomposition of the explained gender gap

\begin{tabular}{|c|c|c|c|}
\hline Variable & Contribution & Coefficient & $\begin{array}{l}\text { Contribution } \\
(\%)\end{array}$ \\
\hline YearFE & $\hat{\theta}_{1}$ year & $\begin{array}{l}-0.0026^{* * *} \\
(0.0002)\end{array}$ & -3.50 \\
\hline HospitalFE & $\hat{\theta}_{2}^{\text {hospital }}$ & $\begin{array}{l}+0.0170^{* * *} \\
(0.0005)\end{array}$ & 22.91 \\
\hline MunicipalityFE & $\hat{\theta}_{3}$ municipality & $\begin{array}{l}+0.0021^{* * *} \\
(0.0001)\end{array}$ & 2.83 \\
\hline ProcedureFE & $\hat{\theta}_{4}$ procedure & $\begin{array}{l}+0.0124^{* * *} \\
(0.0008)\end{array}$ & 16.71 \\
\hline PriorityFE & $\hat{\theta}_{5}$ priority & $\begin{array}{l}+0.0582^{* * *} \\
(0.0009)\end{array}$ & 78.44 \\
\hline AgeFE & $\hat{\theta}_{6}^{\text {age }}$ & $\begin{array}{l}-0.0181^{* * *} \\
(0.0001)\end{array}$ & -24.39 \\
\hline SpecialityFE & $\hat{\theta}_{7}^{\text {speciality }}$ & $\begin{array}{l}+0.0016^{* * *} \\
(0.0004)\end{array}$ & 2.16 \\
\hline CancerFE & $\hat{\theta}_{8}^{\text {cancer }}$ & $\begin{array}{l}+0.0036^{* * *} \\
(0.0001)\end{array}$ & 4.85 \\
\hline Total & $\hat{\delta}^{\text {gender }}$ & +0.0742 & 100 \\
\hline
\end{tabular}

${ }^{* * *} p<0.01$. The robust standard errors are in parentheses.

covariates are included without interactions, while the third column shows the estimation of Equation 2 with the interaction between the municipality of residence and patient's age-fixed effects for a better control for a patient's socioeconomic status.

The unadjusted model estimation shows that, on average, women wait longer, with a gross gender gap of $10.6 \%$ of waiting time. After controlling for multiple sources of observed and unobserved heterogeneity in Equation 2, the gap reduces to $3.1 \%$, showing that a significant unexplained difference in the waiting times of men and women still persists.

The inclusion of the interaction between the municipality and patient's age-fixed effects is not relevant in changing the unexplained gender gap (in comparison with specification of column 2), and so we opted to include all the covariates separately for the following estimations.

Table 3 uses Gelbach's decomposition to show the contribution of each source of heterogeneity (covariate) to the explained gender gap in waiting times.

As expected, adding all the coefficients in Table 3, we get the value of 7.4 percentage points corresponding to

Explaining the Gender Gap in Waiting

Times for Surgery
Table 4. Gender gap by medical specialty

\begin{tabular}{ll}
\hline Specialty & $\hat{\beta}^{\text {adjusted }}$ \\
\hline Ophthalmology & $+0.0187^{* * *}$ \\
General surgery & +0.0078 \\
Orthopaedic & $+0.0214^{* * *}$ \\
Otolaryngology & -0.0017 \\
Urology & $+0.0492^{* * *}$ \\
Plastic surgery and reconstruction & $+0.0515^{* * *}$ \\
Vascular surgery & +0.0221 \\
Dermatology & -0.0204 \\
Neurosurgery & $+0.0569^{* * *}$ \\
Stomatology & $+0.0467^{* *}$ \\
Cardiothoracic surgery & $+0.0369^{*}$ \\
\hline \multirow{2}{*}{$* * * p<0.01 ; * * p<0.05 ; * p<0.10}$. & \\
\hline
\end{tabular}

the $\hat{\delta}^{\text {gender }}$. The patient's initial priority is the covariate that contributes most to the explained gap (78\%), indicating that a large part of the gender gap can be explained by the fact that men have more severe priorities (which have shorter waiting times). Hospital-fixed effects contribute about $23 \%$ to the explained gender gap, followed by surgical procedures-fixed effects at $17 \%$. These results seem to indicate that women are slightly more concentrated in surgical procedures associated with longer waiting times while the distribution of men across hospitals tends to favour those with shorter average waiting times. Agefixed effects present an opposite sign, with minus $24 \%$. This means that women on the waiting lists tend to be concentrated in age groups that have shorter average waiting times.

The remaining fixed effects are less relevant in explaining the gender gap, but still significant: there is a higher concentration of women in municipalities with longer waiting times, there is a higher concentration of men reporting cancer (shorter average waiting times) and being treated in specialties with shorter waiting times, and there is a higher concentration of women operated on in years with shorter waiting times.

\section{Robustness Checks}

We perform robustness checks to assess the consistency of the gender gap previously identified. First, we estimate Equation 2 separately for each of the most frequent medical specialties as well as for different age groups (Tables 4,5 ). Observing the gender gap by age groups with the municipality-fixed effects gives higher control for socioeconomic status, since the age factor is 
Table 5. Gender gap by age group

\begin{tabular}{ll}
\hline Age, years & $\hat{\beta}^{\text {adjusted }}$ \\
\hline$<15$ & -0.0118 \\
$15-30$ & $+0.035^{* * *}$ \\
$30-45$ & $+0.0252^{* * *}$ \\
$45-60$ & $+0.0396^{* * *}$ \\
$60-75$ & $+0.0407^{* * *}$ \\
$\geq 75$ & +0.0072 \\
\hline
\end{tabular}

$* * * p<0.01$

Table 6. Estimation with sub-samples of observations

\begin{tabular}{ll}
\hline Scenario & $\hat{\beta}^{\text {adjusted }}$ \\
\hline A & $+0.0252^{* * *}$ \\
B & $+0.0318^{* * *}$ \\
C & $0.052-0.0535^{* * *}$ \\
\hline \multirow{2}{*}{$* * * p<0.01}$. & \\
\hline
\end{tabular}

said to be crucial in explaining gender differences due to income or educational background.

Table 4 shows a pattern in which women have, on average, longer waiting times for surgery. Although otolaryngology and dermatology present an opposite sign, the coefficients are not statistically significant. In Table 5, we observe a similar pattern, where women have longer waiting times. The age group $<15$ years presents an opposite sign (without statistical significance).

We then estimate Equation 2 and exclude observations that might unduly bias the results. In scenario A, we exclude the top $10 \%$ of waiting times for surgery, because there could be an abnormal number of women in these outlier observations. In scenario B, we eliminate patients who were on the waiting list for $<1$ day, because patients who were admitted through the emergency department could be treated differently.

In scenario $\mathrm{C}$, we perform an additional check to see the impact on the adjusted gender gap if we focus on a number of categories for a given variable due to computational constraints, e.g., instead of including them all with the most flexible parametric specification, as we have estimated. To demonstrate this, we take the surgical procedure variable (the variable with the largest number of categories), and we include a dummy for each of the 100 most common procedures, coding the remaining catego- ries as "others." We also test for the 150 and 200 most common procedures. Table 6 shows the estimates.

The results confirm that the estimate of a gender gap is robust; in all scenarios, women have, on average, longer waiting times. Scenario C shows that the gender gap is overestimated when focusing on a specific number of surgical procedures. This result reveals that a more flexible specification guarantees a more accurate estimate for the unexplained gender gap, so the high-dimensional fixedeffects model may play an important role when the number of categories is too high to allow for estimation by conventional methods.

\section{Discussion}

The use of a methodology suitable for estimating a high-dimensional fixed-effects model allowed us to control for a set of covariates that would not be possible to include in the model using the conventional approach. We did try to use the standard approach and estimate an OLS model, but that was not feasible due to computer memory limitations. To the best of our knowledge, there are no previous studies on waiting times for health care that used this approach (which is essential to quantify the gender bias in waiting times properly).

The initial $10.6 \%$ gross gender gap estimate was reduced to an unexplained gender gap in which women wait $3.1 \%$ longer than men after controlling for a set of covariates.

This represents a difference of only 1 day between genders, which is much less than the literature has previously suggested. Nevertheless, it is a significant unexplained difference that could be considered an estimate of the degree of discrimination towards women. However, one may not conclude without reservation that such a degree of discrimination exists, because there may be other factors for which we did not control (e.g., ethnicity or employment status/professional activity), which might also explain the gender gap. This is one limitation of our study, since patients' socioeconomic data was not available.

The application of Gelbach's decomposition allowed us to identify the contribution of each factor to the explained gender gap of 7.4 percentage points. The patient's initial priority is the variable that explains most of that disparity, suggesting that men are classified as having more severe priorities which, in turn affects waiting times, since higher degrees of severity have shorter waiting times. This result may be explained by the literature that found men utilise health care less and display a worse 
clinical condition when they do get access to treatment [12]. However, if there are substantial variations in the way men and women present illness symptoms and communicate their clinical condition $[9,11]$, the chance of patient prioritisation suffering from gender bias cannot be excluded. Gender discrimination in patient prioritisation could be justified, for instance, by the fact that doctors may assume that men still use health care later, or that men are stronger and more likely to take risks, when compared to women [32]. The literature shows that health professionals are not exempt from displaying implicit bias (prejudice and stereotype) similar to that presented by the general population [33], and given existing prejudice like "the intrinsic role of women providing care at home and men being breadwinners" [34], men may be seen by doctors as the primary financial provider in the household, which may result in higher priorities for men, so that they are able to return to work quickly.

Hospital-fixed effects are the second factor that contributes most to the gender gap, indicating that there are hospital specificities that cause men to have shorter waiting times. This result may corroborate the hypothesis of gender bias exhibited by health professionals by "routines" or "distorted content in established medical knowledge" [11].

These findings suggest the need for audits of hospital activity to identify the reasons for the reported differentials as well as hospital gender-sensitive health indicators to increase transparency and assess its comparability and progress. Moreover, gender-sensitivity training for health professionals is advised for raising awareness of the issue of gender bias [35].

Finally, if differences in priorities between men and women represent actual differences in clinical conditions (if men really have worse clinical conditions), our results recommend better monitoring of men's health, in primary health care institutions or in occupational medicine, to reduce risk behaviours and to identify health problems at an earlier stage.

\section{Conclusion}

This study analyses the gender gap in waiting times for scheduled surgery in the Portuguese NHS. We used data from 2011 to 2015 and a model that allowed us to account for multiple sources of heterogeneity, using a highly flexible parametric specification to obtain an estimate for the adjusted gender gap.

Explaining the Gender Gap in Waiting Times for Surgery
We found that, after controlling for various sources of observed heterogeneity, a small but significant gender bias persists, with women waiting 3\% longer for surgery, although this bias is much smaller than the gross $10 \%$ gap between genders that was estimated without controlling factors. The decomposition of the explained gender gap confirms a pattern that suggests women are discriminated against regarding access to surgery, even though the size of the gender bias is much smaller than previous literature suggested.

\section{Statement of Ethics}

Ethics approval was not required due to the nature of the study.

\section{Conflict of Interest Statement}

The authors declare there are no conflicts of interest.

\section{Funding Sources}

This research has been financed by the European Regional and Development Fund (ESF) and by Portuguese Public Funds through Fundação para a Ciência e Tecnologia (FCT) in the framework of the PhD Scholarship: SFRH/BD/115954/2016.

\section{Author Contributions}

All authors made substantial contributions to all aspects of the work.

\section{References}

$$
\begin{aligned}
& 1 \text { Johar M, Jones G, Keane MP, Savage E, } \\
& \text { Stavrunova O. Discrimination in a universal } \\
& \text { health system: explaining socioeconomic } \\
& \text { waiting time gaps. J Health Econ. } 2013 \text { Jan; } \\
& \text { 32(1):181-94. } \\
& 2 \text { Landi S, Ivaldi E, Testi A. Socioeconomic sta- } \\
& \text { tus and waiting times for health services: an } \\
& \text { international literature review and evidence } \\
& \text { from the Italian National Health System. } \\
& \text { Health Policy. } 2018 \text { Apr;122(4):334-51. } \\
& 3 \text { Laudicella M, Siciliani L, Cookson R. Waiting } \\
& \text { times and socioeconomic status: evidence } \\
& \text { from England. Soc Sci Med. 2012 May;74(9): } \\
& \text { 1331-41. } \\
& 4 \text { Cooper ZN, McGuire A, Jones S, Le Grand J. } \\
& \text { Equity, waiting times, and NHS reforms: ret- } \\
& \text { rospective study. BMJ. 2009 Sep;339:b3264. } \\
& 5 \text { Łyszczarz B. Gender bias and sex-based dif- } \\
& \text { ferences in health care efficiency in Polish re- } \\
& \text { gions. Int J Equity Health. 2017 Jan;16(1):8. }
\end{aligned}
$$


6 Read JG, Gorman BK. Gender and health inequality. Annu Rev Sociol. 2010;36(1):37186.

7 McDonough P, Walters V. Gender and health: reassessing patterns and explanations. Soc Sci Med. 2001 Feb;52(4):547-59.

8 Arber S. Comparing inequalities in women's and men's health: Britain in the 1990s. Soc Sci Med. 1997 Mar;44(6):773-87.

9 Alspach JG. Is there gender bias in critical care? Crit Care Nurse. 2012 Dec;32(6):8-14.

10 Bertakis KD, Azari R, Helms LJ, Callahan EJ, Robbins JA. Gender differences in the utilization of health care services. J Fam Pract. 2000 Feb;49(2):147-52.

11 Hamberg K. Gender bias in medicine. Womens Health (Lond). 2008 May;4(3):237-43.

12 Payne $\mathrm{S}$. How can gender equity be addressed through health systems? Copenhagen: World Health Organization; 2009. (Policy Brief; 12).

13 Kuhlmann E, Annandale E. Gender and healthcare policy. In: Kuhlmann E, Blank RH, Bourgeault IL, Wendt C, editors. The Palgrave international handbook of healthcare policy and governance. London: Palgrave Macmillan; 2015.

14 Kuhlmann E, Annandale E, editors. The Palgrave handbook of gender and healthcare. London: Palgrave Macmillan; 2012.

15 Kaarboe O, Carlsen F. Waiting times and socioeconomic status. Evidence from Norway. Health Econ. 2014 Jan;23(1):93-107.

16 Abásolo I, Negrín-Hernández MA, Pinilla J. Equity in specialist waiting times by socioeconomic groups: evidence from Spain. Eur J Health Econ. 2014 Apr;15(3):323-34.
17 Moscelli G, Siciliani L, Gutacker N, Cookson R. Socioeconomic inequality of access to healthcare: does choice explain the gradient? J Health Econ. 2018 Jan;57:290-314

18 Smirthwaite G, Lundström M, Wijma B, Lykke N, Swahnberg K. Inequity in waiting for cataract surgery-an analysis of data from the Swedish National Cataract Register. Int J Equity Health. 2016 Jan;15(1):10.

19 Lasch V, Sonntag U, Maschewsky-Schneider U. Equity in access to health promotion, treatment and care for all European women. Kassel: Kassel University Press; 2010.

20 Perelman J, Fernandes A, Mateus C. Gender disparities in health and healthcare: results from the Portuguese National Health Interview Survey. Cad Saude Publica. 2012 Dec; 28(12):2339-48.

21 Verbrugge LM, Steiner RP. Physician treatment of men and women patients: sex bias or appropriate care? Med Care. 1981 Jun;19(6): 609-32.

22 Foss C, Sundby J. The construction of the gendered patient: hospital staff's attitudes to female and male patients. Patient Educ Couns. 2003 Jan;49(1):45-52.

23 European Commission. Report on equality between women and men in the European Union. Brussels: European Commission; 2019.

24 Gutacker N, Siciliani L, Cookson R. Waiting time prioritisation: evidence from England. Soc Sci Med. 2016 Jun;159:140-51.

25 Barros P, Cristovão R, Gomes P. Portugal. Waiting time policies in the health sector: what works? Paris: OECD Publishing; 2013.

26 Gomes P, Lapão LV. The SIGLIC system for improving the access to surgery in Portugal. Electron Inf Syst Eval. 2011;14:160-6.
27 Portugal. Ministério da Saúde. ACSS. Acesso a cuidados de saúde nos estabelecimentos do sns e entidades convencionadas em 2016: relatório anual. Lisboa: Administração Central do Sistema de Saúde; 2017.

28 Guimarães P, Portugal P. A simple feasible procedure to fit models with high-dimensional fixed effects. Stata J. 2010;10(4):628-49.

29 Gelbach JB. When do covariates matter? And which ones, and how much? J Labor Econ. 2016;34(2):509-43.

30 Cardoso AR, Guimarães, Portugal P. What drives the gender wage gap? A look at the role of firm and job-title heterogeneity. Oxf Econ Pap. 2016;68(2):506-24.

31 Correia S. Linear models with high-dimensional fixed effects: an efficient and feasible estimator. Durham, CA: Duke University; 2017. (Working Paper).

32 Daugherty SL, Blair IV, Havranek EP, Furniss A, Dickinson LM, Karimkhani E, et al. Implicit gender bias and the use of cardiovascular tests among cardiologists. J Am Heart Assoc. 2017 Nov;6(12):e006872.

33 FitzGerald C, Hurst S. Implicit bias in healthcare professionals: a systematic review. BMC Med Ethics. 2017 Mar;18(1):19.

34 Pinillos-Franco S, Somarriba N. Examining gender health inequalities in Europe using a Synthetic Health Indicator: the role of family policies. Eur J Public Health. 2019 Apr;29(2): 254-9.

35 Lindsay S, Rezai M, Kolne K, Osten V. Outcomes of gender-sensitivity educational interventions for healthcare providers: a systematic review. Health Educ J. 2019;78(8): 958-76. 